\title{
Experimental and Numerical Analysis of Battened Built-up Lightweight Concrete Encased Composite Columns subjected to Axial Cyclic loading
}

\author{
N.Divyah $^{\mathrm{a}^{*}}$ (D), R.Thenmozhi ${ }^{\mathrm{a}}$ (D), M.Neelamegam ${ }^{\mathrm{b}}$ \\ aGovernment College of Technology, Coimbatore, India. E-mail: divyah991@gmail.com, drthenmozhi@gct.ac.in \\ bEaswari Engineering College, Chennai, India. E-mail: mnmegam@gmail.com \\ * Corresponding author
}

http://dx.doi.org/10.1590/1679-78255745

\begin{abstract}
In the recent era, built-up columns have been continuously used by the engineers in the design and analysis of tall buildings and bridges. Vibration analysis of these types of columns is essential to understand the failure modes of such columns. In that aspect, this study aims to analyze a concrete-encased built-up column made by configuring cold-formed steel angle sections connected by means of battens encased by normal weight and lightweight concrete with and without the inclusion of basalt fibre. Eight columns with battens were simulated, and it is encased with four different types of concrete and subjected to axial cyclic loading. The experimental results were correlated with the numerical investigation performed using FEA. The results indicated that the type of concrete dramatically influences the behaviour of columns. Higher ultimate strength and ductility was observed for all specimens, which is due to lower shear capacity of the battens. It was observed that the intensity of the axial cyclic load has a significant effect on the ultimate strength and deflection of columns, but it is less influential on the yield strength. It was concluded the results of experimental and FEA shows good compatibility between each other and depicts an error of $7.48 \%$.
\end{abstract}

Keywords

Battened built-up Column, Sintered Fly ash lightweight concrete, Basalt Fibre, Deformation, Strain Behaviour, FEA

\section{Graphical Abstract}

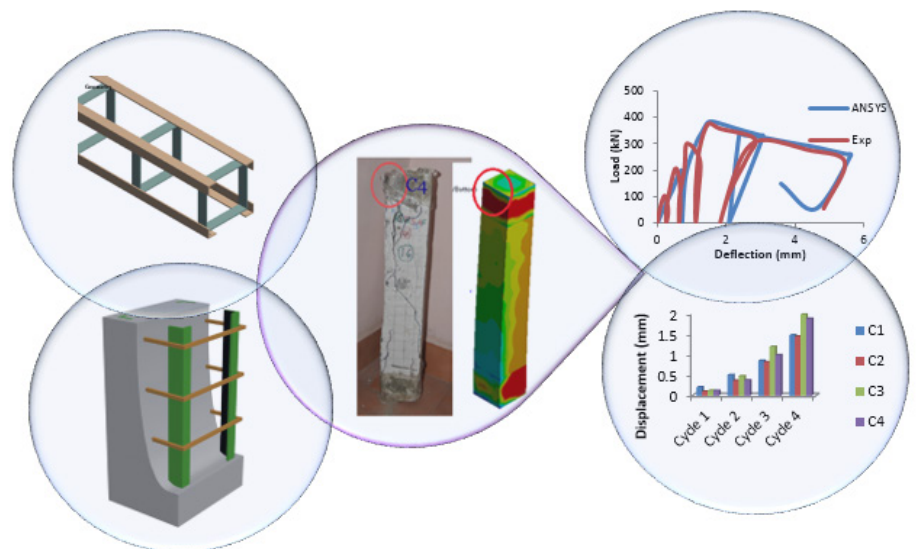




\section{INTRODUCTION}

The steel-concrete composite columns are not well pronounced for its behavioural aspects as conventional reinforced columns, due to traditional separation between-steel and concrete. The difference in codal provisions for concrete-encased composite columns proves to be a proof for such conflicts. Moreover, the codes governing reinforced concrete design provides sufficient ductility and also the concrete is well confined (Muguruma et al., 1991). However, the inadequate codal provisions on confinement effects of reinforced concrete and encased composite columns are always uncertain (Collins et al. (1993). Numerous researches are in progress in steel-concrete built-up columns to identify precisely the behaviour of such members under various loading conditions.

A battened built-up column is a one-type compression member consisting of two identical longitudinal elements separated by a small distance and connected to each other by means of battens at some predefined spacing. The steel core itself is self-supporting and can be used in steel structures without any encasement (AISC. (2001). Double channel sections often comprise the longitudinal element in battened columns. The axial buckling strength of these columns are low due to increased shear deflections or due to compound buckling (Duan L, Reno M, Uang C.(2002) when compared to solid columns.

The axial buckling strength is significantly governed by the endplates in battened members as they are responsible for even distribution of the applied forces or moments to the compound elements (Bleich F.(1952). Up on seismic loading or vibration loading, the battened columns undergo large compressive strains with large lateral deformations with the formation of a plastic hinge at critical sections at the points of maximum moments in addition to the axial compression (Lin FJ, Glauser EC, Johnston BG (1970). The performance of these plastic hinges greatly influences the ductility (Sherif El-Tawil, Gregory G. Deierlein (1999) and hence the energy dissipation capacity. The severity of local buckling can be reduced by smaller width-to-thickness ratio, thus increasing the ductility and energy dissipation capacity (Aslani F, Goel SC. (1991a); (Aslani F, Goel SC. (1991b);Astaneh-Asl A, Goel SC, Hanson RD. (1985).

The use of lightweight concrete as encasement can substantially reduce the self-weight of the columns. It consecutively boosts the speed of construction and also reduced thickness of column can be achieved. The lightweight concrete can be made by using either natural or artificial lightweight aggregates. They can be proportioned in such a way that it behaves better than normal-weight concrete. Inclusion of basalt fibre in the concrete matrix improves the ductility and energy absorption capacity of the columns.

The present study is aimed to evaluate the characteristics of a typically designed lightweight concrete-encased battened built-up composite short column under axial cyclic loading. These columns find its applications in vibration effects on structures mostly dancing floors, buildings with machine foundations and floors with vibrating machinery. Initially, the load-carrying capacity of the columns was evaluated upon axial loading. Then the columns were subjected to axial cyclic loading in a 50T loading frame. A numerical investigation is carried out using ANSYS 16.1 package, and the results are validated.

\subsection{Proposed system}

The battened composite short column is formed by placing angle sections longitudinally on all the four corners. These angle sections are separated by a predefined distance and are connected to each other using batten plates with specific predesigned spacing (Dipti R. Sahoo, Durgesh C. Rai. (2007). For this purpose, cold-formed steel plates are made to the desired shape and size in the power press brake. Figure 1 shows a typical 3D layout of the configuration used. This steel core is used instead of conventional reinforcement and is encased by concrete. As the concrete hardens the steel core together with the encased concrete makes up the concrete-encased composite column. The capacity of the built-up section is increased considerably depending upon the nature of concrete. 


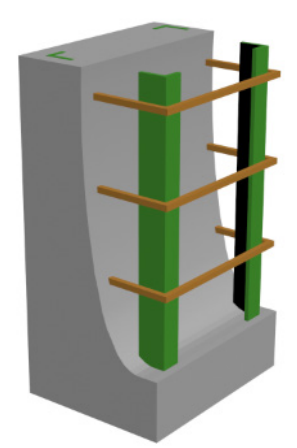

Figure 1 Typical 3D layout of the column

In order to study the effect of concrete that acts as encasement, four types of concrete: Normal weight concrete, basalt fibre reinforced normal weight concrete, Lightweight concrete, basalt fibre reinforced lightweight concrete. With the effect of the composite action between the steel and concrete elements, the performance beyond what is expected is expected.

\section{EXPERIMENTAL PROGRAM}

The main variables considered in the experimental investigation are Lightweight concrete, the effect of loading and basalt fibre inclusion. The fundamental behaviour under axial cyclic loading, load-deflection response, ductility behaviour, ultimate load carrying capacity, the effect of fibre inclusion, stiffness, energy absorption and failure modes of concrete-encased built-up composite columns are studied. Emphasis is given to the behavioural aspects: how the materials interact (Galambos TV. (1998) and how the failure of the concrete core progresses to improve its performance.

The length of the short columns was chosen to be short enough so that the section strength governs the resistance of the column, but long enough to minimize any end effects upon their response. The details of column cast for the investigation are given in Figure 2, and their engineering properties are given in Table 1. Cold-formed sheets of thickness 1.6mm confirming to Indian standards (BIS 801. (1975 - Reaffirmed 2010), BIS. 800. (2007) were used for fabrication of angle sections and for plates that make up the battens. The yield strength $f_{y}$ of steel sheet is found as 260.34MPa by coupon test. Basalt fibre of length $18 \mathrm{~mm}$ is added as a secondary reinforcement to improve the ductile behaviour and energy absorption capacity of the columns. The normal-weight concrete is made with locally available conventional aggregates. The sintered fly ash aggregate is used for making the lightweight concrete.

Table 1 Properties of concrete-encased composite column

\begin{tabular}{rccccc}
\hline $\begin{array}{r}\text { SI } \\
\text { No. }\end{array}$ & Column ID & Type of Concrete & $\begin{array}{c}\text { E } \\
\mathbf{f}_{\text {ck }} \\
\text { (MPa) }\end{array}$ & $\begin{array}{c}\text { Dimensions } \\
\text { (GPa) }\end{array}$ \\
\hline 1 & C1 & Normal-weight concrete & 38.04 & 30.504 \\
2 & C2 & Fibre reinforced Normal-weight concrete & 40.56 & 35.317 & $100 \mathrm{~mm} \times 100 \mathrm{~mm} \times 700 \mathrm{~mm}$ \\
3 & C3 & Lightweight concrete & 38.62 & 22.374 & $100 \mathrm{~mm} \times 100 \mathrm{~mm} \times 700 \mathrm{~mm}$ \\
4 & C4 & Fibre reinforced lightweight concrete & 41.88 & 29.949 & $100 \mathrm{~mm} \times 100 \mathrm{~mm} \times 700 \mathrm{~mm}$ \\
\hline
\end{tabular}

The size of the aggregate for the mix had to be carefully selected to obtain a gradation that would provide a concrete encasement around and inside the steel sections most suitable for a small-scale specimen. Hence, aggregates of size $12 \mathrm{~mm}$ down passing were used as coarse aggregates. The cover to the steel core is chosen to be $20 \mathrm{~mm}$. The specimens were fabricated carefully and cured in ambient temperature for 28 days under laboratory-controlled environment.

A major problem in column testing is to define precisely the line of action of the force. Second-order effects in columns are incorrectly reproduced unless the line of action of the applied axial load passes through the interaction of the axes of the column. A steel plate capping on the column ensures even spread of the load. A steel capping plate was fabricated and was kept at top and bottom to ensure fixity conditions and to facilitate axial loading conditions. Each composite column is appropriately wrapped with high strength GFRP sheets at top and bottom for $100 \mathrm{~mm}$ so that the local crushing at the point of application of the load and premature failure of the column is avoided. 

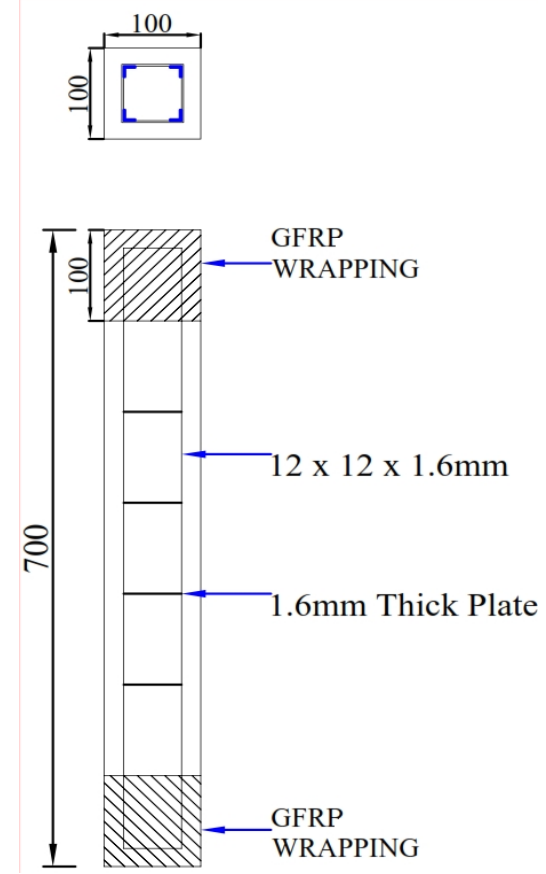

Figure 2 Battened steel built-up column

\subsection{Experimental Set-Up}

The columns were tested for axial cyclic loading with the following arrangements, in a loading frame of 50T capacity. The schematic diagram and complete test set up used for the specimens are shown in Figure 3. The column was loaded for cyclic axial compression from the basic idea obtained from IS 516 (1959) and improved testing methods for composite columns were obtained from previous studies (Y.J. Kim, M.H. Kim, I.Y. Jung, Y. K. Ju, and S.D. Kim (2011). The load was applied through end steel plates at the top and bottom of the specimen. Proper care was taken to maintain the verticality of the specimen. The specimens were instrumented with dial gauges - at $1 / 3 \mathrm{rd}$ point, mid-point and $2 / 3 \mathrm{rd}$ point to measure the lateral deflection. The axial shortening was measured by fixing an LVDT vertically with the column endplate (S.M. Mourad, M.J. Shannag (2012). The linear and lateral strains were measured by fixing strain gauges (Jothimani B, Umarani C. 2019)parallel and perpendicular to the column axis at the center point and are connected to 10 channel strain indicator. The load cell is placed over the column and is connected to a digital load indicator. The load is applied using a hydraulic jack of 50T capacity connected to a power pack. The column to be tested is rigidly fixed using the steel capping plates at top and bottom. To ensure even distribution of loads and to avoid premature crushing of columns, the top and bottom faces of the column are levelled using a high strength plaster and high strength GFRP sheets. Initially, the ultimate load of each column were found by testing the columns under axial monotonic compressive loading. Then the load intervals were fixed based on the ultimate load carried by the columns. The deflection and strain values for each load increment are noted.

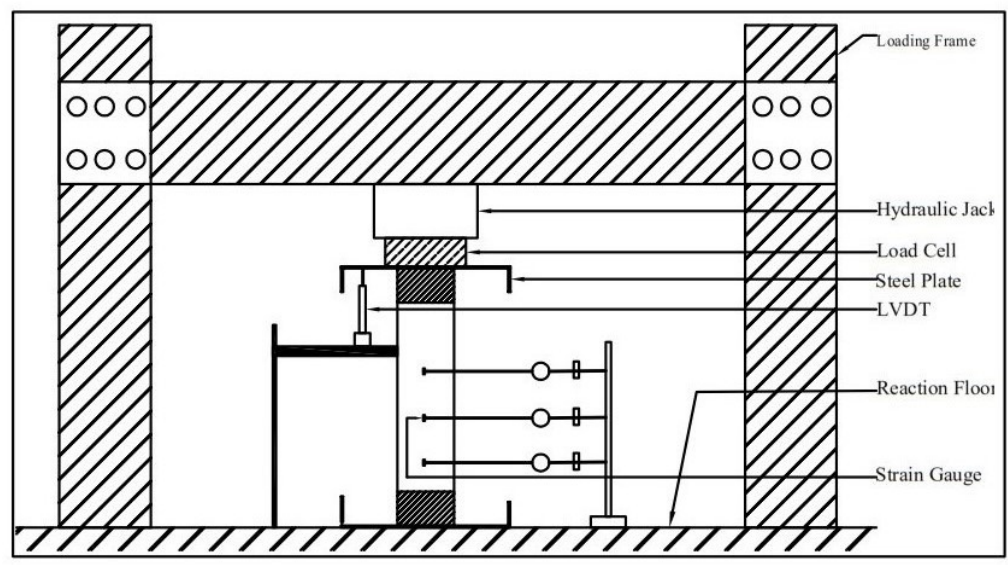

Figure 3 Schematic test arrangement 


\subsection{Finite Element Analysis}

The finite element analysis is an essential numerical tool that was used as a reference study for the columns tested. For this purpose, the ANSYS software package was used to create the dimensions and properties of the columns tested. The analysis is carried out with an assumption that the behaviour of the columns can be described by a plane stress field. The shape functions are chosen to approximate the variation of displacement at the nodes of the element. The strains and stresses within an element can also be expressed in terms of the nodal displacement. The principle of virtual displacement is used to derive the equations of equilibrium for the element, and the nodal displacement is the unknowns in the equations.

In this analysis, concrete, steel and GFRP sheets were represented by different material models and interaction is created between these elements through interaction models. Non-linear three-dimensional finite element models of the column were developed to account for the geometry, material, loading and boundary condition. The non-linear finite element analysis was used as a primary tool to compare the results of experimental investigation previously carried out. ANSYS design modeller environment was utilized to create the model the reinforcement (1D model) using a concept tool and concrete model (3D model). The steel reinforcement detailing of the column is created as wireframe structures in accordance with the details followed in the experimental analysis. The pictorial representation of the model of the column is shown in Figure 4 and 5, and it is mesh modelling. Displacement boundary conditions are applied to constraint the model to get a unique solution. To ensure that the model acts the same way as the experimental column, boundary conditions need to be applied at faces, as shown in Figure 6 .

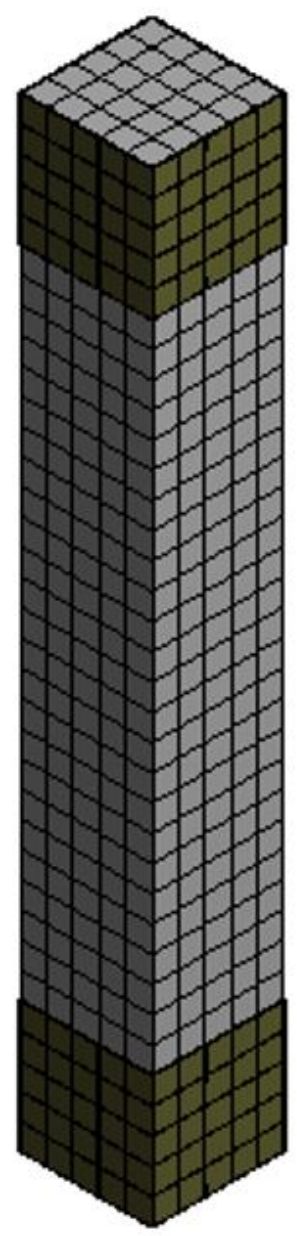

Figure 4 Meshed concrete model 


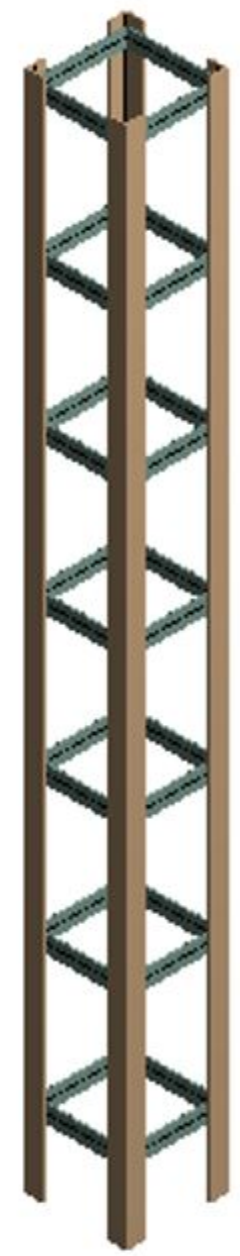

Figure 5 Meshed reinforcement

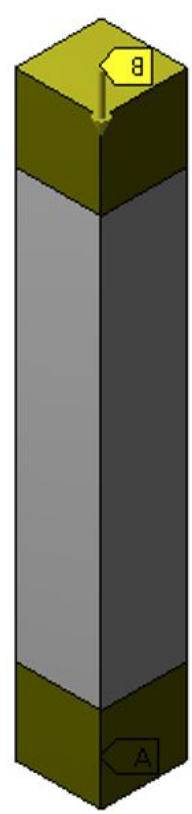

Figure 6 Applied boundary conditions 


\section{RESULTS AND DISCUSSION}

In this section, the lateral load-displacement hysteresis curves are presented, and the ductility, strength and stiffness reduction, energy absorption capacity and the failure modes of the test specimens are discussed.

\subsection{Observed behaviour and failure mode}

On loading, the response of the column specimens under each load increment and decrement was observed. Vertical minor cracks were first developed on the concrete, and, subsequently, these cracks started enlarging. At failure, the cracks started propagating throughout the length of the specimens and resulted in final crushing. Almost after the ultimate load, the GFRP sheet started tearing at the corners, as indicated in Figure 7, and it presents the failure appearance of the specimens at the failure load.
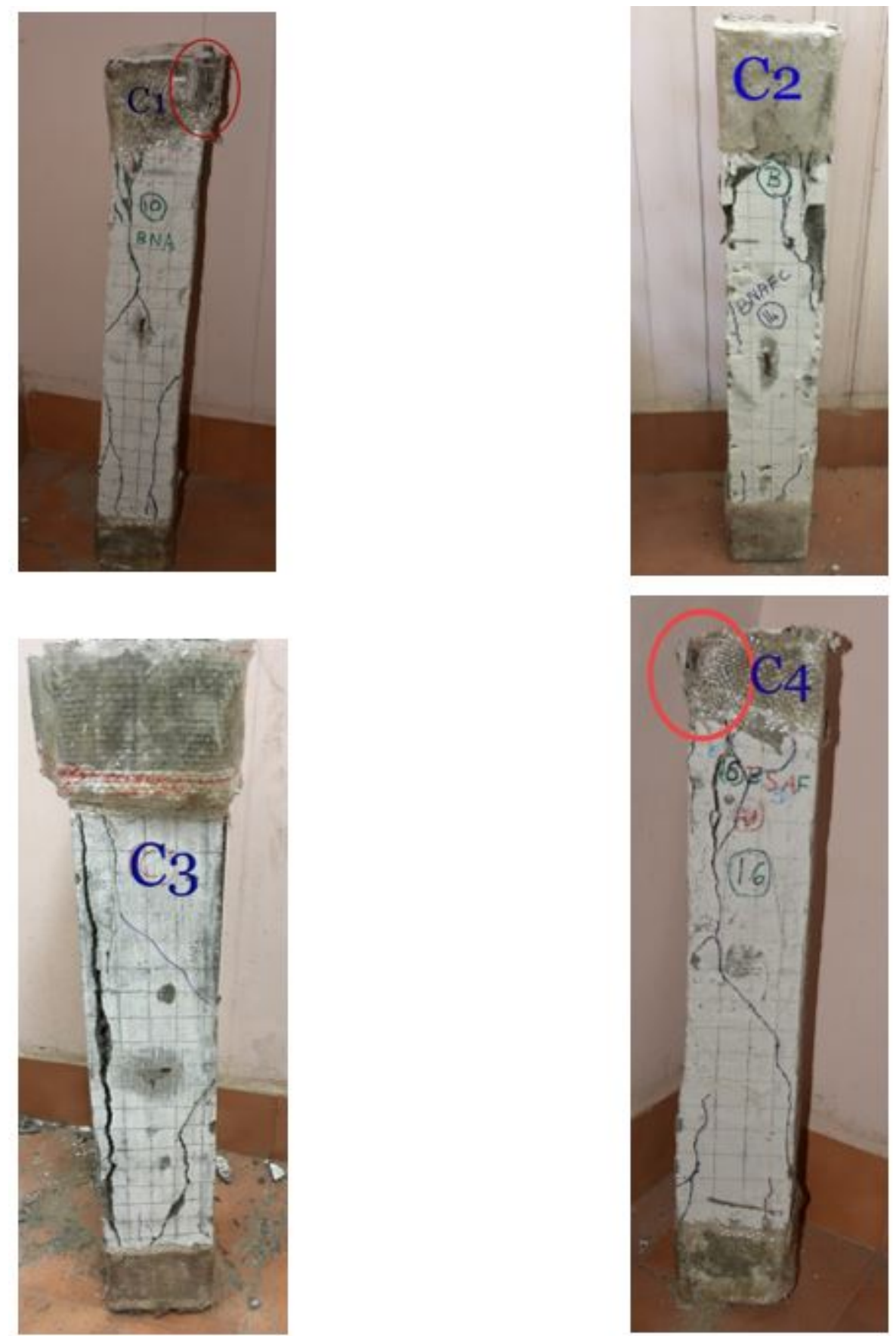

Figure 7 Failure modes of column 
The column C1 was pronounced with a minor crack on the starting of the second cycle, and it started propagating at each load increments. At the 3rd cycle, this minor crack transformed to a major crack at $290 \mathrm{kN}$ and small numbers of minor cracks started appearing at the top and middle portions of the column. The ultimate load was reached at the $4^{\text {th }}$ cycle, and failure occurred at the 5th cycle. It was noted that a major crack started widening throughout the length of the specimen and after the ultimate load, the GFRP sheet started tearing up at one corner at the top. The specimen had suffered crushing at the top surface, but the high strength plaster and high strength GFRP layers had resisted the premature crushing effect. On observing the failure pattern of column $\mathrm{C} 2$, this column constitutes $0.25 \%$ of basalt fibre in it. It was pronounced with more number of minor cracks than the latter. At the 3 rd cycle, a major crack started appearing, and with further load increment, it started propagation along the sides. At the 4th cycle, a layer of concrete at the corner of the specimen below the GFRP layer started crushing. For the column C3 with sintered fly ash aggregate concrete, a major crack appeared at $250 \mathrm{kN}$ almost near the ultimate load. Very few minor cracks were observed on the specimen. The specimen failed with a large major crack that propagated alongside one corner of the specimen. At the 4th cycle, a crack started propagating from the bottom side of the specimen. The column C4 is pronounced with some minor cracks, and at 4th cycle, a major crack appeared at the bottom side of the specimen at $302 \mathrm{kN}$. A major crack appeared after further load increment at the top side of the specimen and is propagated along the length of the column, and it constituted the final failure. After the onset of 2 nd major crack, the GFRP layer at one top corner started to tear.

The lightweight concrete column had less minor cracks, but major crack suddenly propagated and failed. Whereas, for the normal-weight concrete column, the minor crack transformed into a sizeable major crack. The normal-weight concrete column with basalt fibre had more number of minor cracks appeared and one of the minor crack transformed to a major crack.

\subsection{Axial shortening}

The axial shortening of the specimens is observed experimentally (Figure 8) by placing an LVDT vertically fitted below the steel plate placed over the column specimen. At the initial phases of load cycles, the normal weight concrete columns had no significant axial deformation. Up to 3 cycles, the deformation of the columns were less than $1 \mathrm{~mm}$. Still, as the cycle reached the ultimate load, the deformation started increasing at a more significant rate that in the next load cycle after ultimate, failure load was obtained. The columns with lightweight concrete without fibre reported $2 \mathrm{~mm}$ deformation after three load cycles and those lightweight columns with basalt fibre reported having only $1 \mathrm{~mm}$ deformation similar to normal weight concrete. These lightweight columns also failed just a cycle after the ultimate load but with deformations $35 \%$ more than the normal-weight concrete columns.

The axial shortening of columns with lightweight concrete is more as the failure of the columns due to concrete can be characterized by crushing and splitting of aggregates along with the load interfaces. Addition of basalt fibre did not affect reducing the axial deformation, and it is evident from the graph. With an increase in axial load cycles, the deformations where more and the load-deflection curves became more rhombic like. (Behrokh Hosseini Hashemi, Alireza Poursamad Bonab. (2013)).
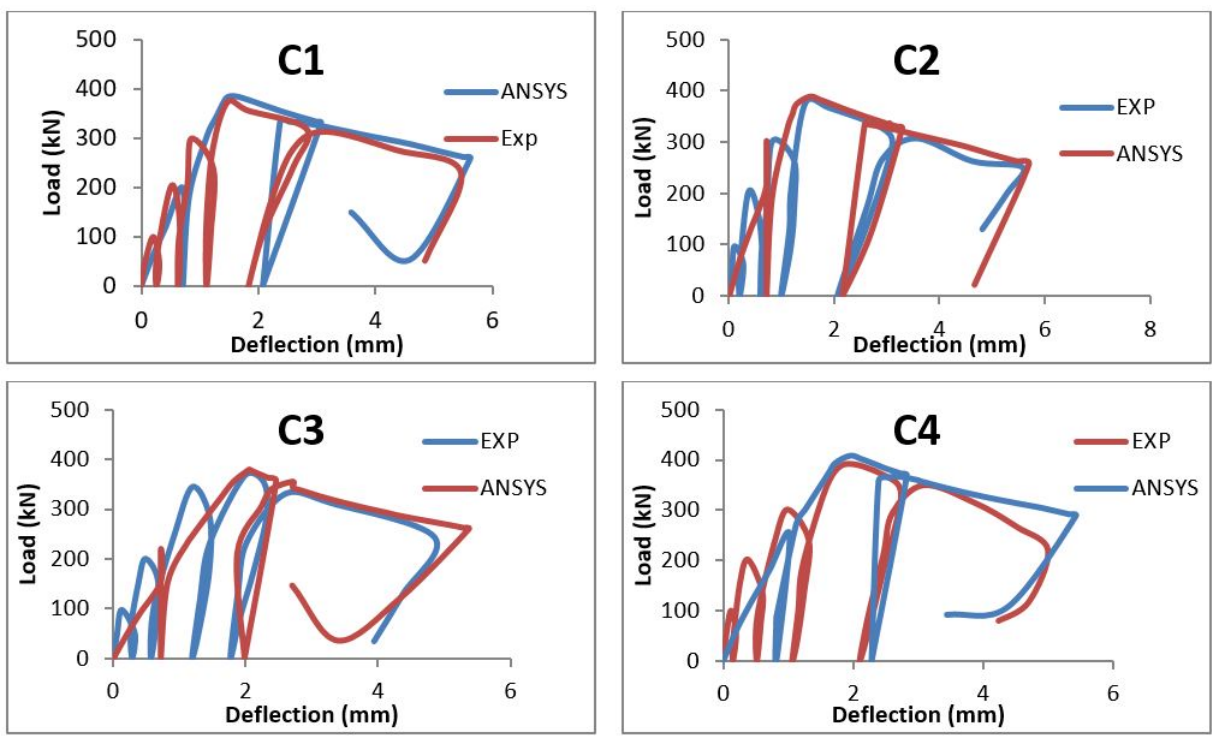

Figure 8 Axial Deformation Pattern of the Specimens 


\subsection{Lateral Deformation at mid-span}

Being short columns, these columns typically fail by crushing, there was significant axial deformation at the initial load cycles itself. But the lateral deformations were significant for all columns after three load cycles only. The columns after reaching the ultimate load started to fail by undergoing large strains without any larger lateral loads. Even the specimens at the ultimate load had only $2 \mathrm{~mm}$ lateral deformation, but with further increase in axial load cycle, the deformation started increasing. It is due to widening of the major cracks along the length of the specimen. As can be seen from the load-deflection curve in Figure 9 the fibre reinforced normal weight columns sustained large loads with more minor cracks that resulted in deformation 1.17 times more than that of the conventional normal weight concrete. Although the ultimate load of lightweight concrete columns and normal weight concrete columns were similar, the lateral deformation of lightweight columns were found to be $15 \%$ lesser than the conventional. The fibre reinforced columns had similar lateral deformation with a difference of about $4 \%$, which is not much significant.
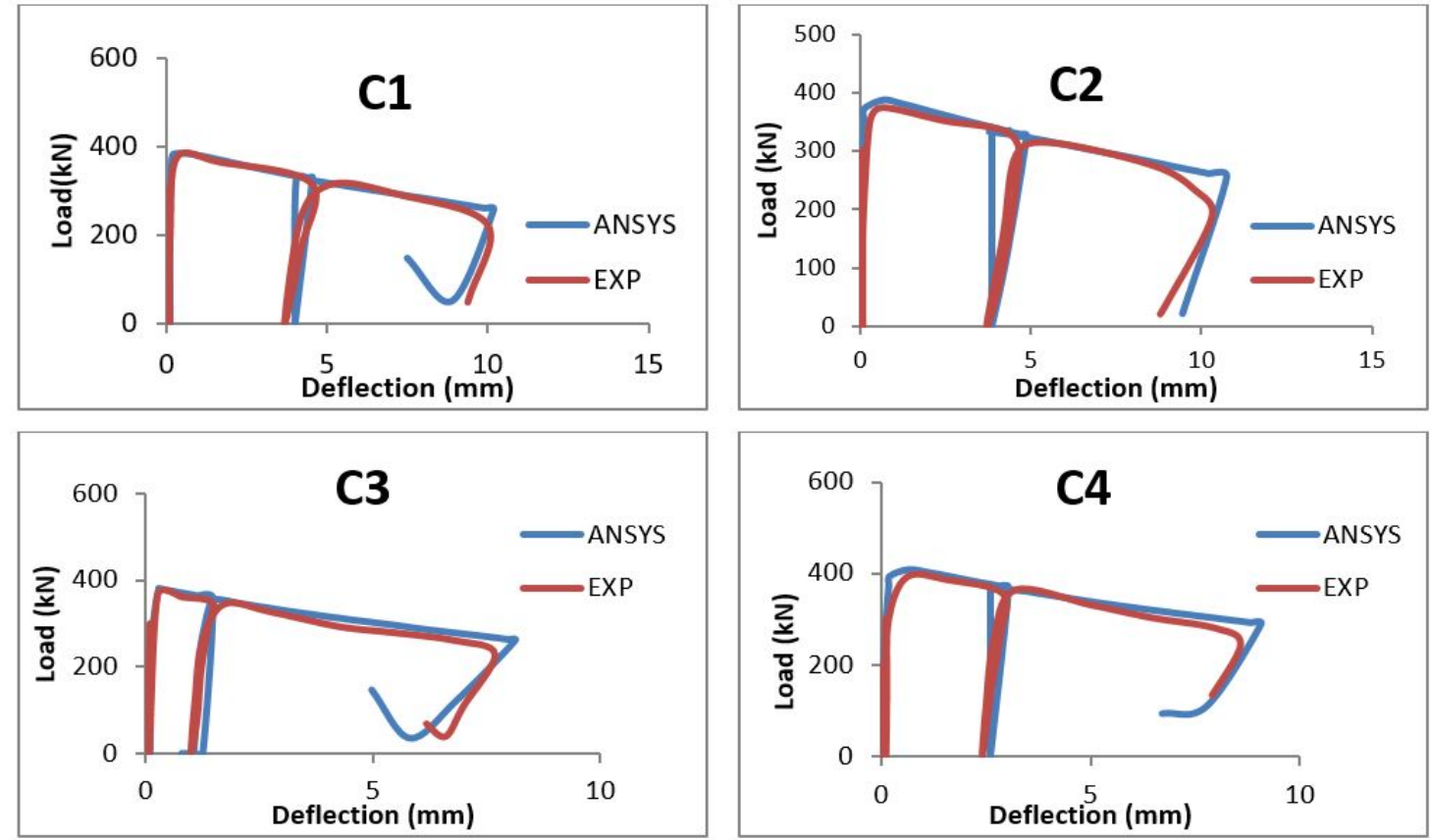

Figure 9 Lateral Mid-point deformation of columns

\subsection{Cracking displacement}

The displacements were measured on the onset of major cracks. From table 2, it can be perceived that the first major cracks appeared just before the ultimate load had reached. After the incidence of the first major crack, with further increment in loading, the crack started widening and resulted in propagation further till final failure. As can be seen that the columns C1 and C3 had similar deflection at the occurrence of the major crack but the columns C2 and C4 had deflections two times more than the latter. But with further load increments, at failure, almost all columns had the same amount of deformation laterally and the lightweight concrete columns had significant axial deformations. The effect of the addition of fibres plays a major role in this behaviour was at the initial phase. However, the deformations are high; the fibres had arrested further widening of cracks, thus resulting in a controlled failure mode and failure deformations similar to that with no fibre.

Table 2 Load and Displacement at Crack formation

\begin{tabular}{cccc}
\hline Column ID & Load & \multicolumn{2}{c}{ Deflection (mm) } \\
\cline { 3 - 4 } & & Axial & Midpoint \\
\hline C1 & 290 & 0.85 & 0.04 \\
C2 & 300 & 0.818 & 0.083 \\
C3 & 250 & 0.927 & 0.05 \\
C4 & 302 & 0.992 & 0.122 \\
\hline
\end{tabular}




\subsection{Yield Displacement}

Being a short compression member, the yield displacement of the column in the axial direction at each load cycles was investigated to analyze the performance of the different types of concrete upon axial cyclic loading. The yield displacement for column $\mathrm{C} 1$ is 1.78 times more than the 1 st cycle, and at the $3 \mathrm{rd}$ cycle, it was about 0.77 times more than the latter. With further increase in load, at the 4th cycle, the yield deformation was 0.53 times more than the previous one. At cycle 2, the column C2 has a yield displacement 2.18 times more than the 1 st cycle. At the 3rd cycle, the yield displacement was 2.26 times more than the 2 nd cycle. After which at the 4 th cycle, the yield displacement was 0.55 times more than the latter. The yield displacement for column C3 is 3.44times more than the 1st cycle, and at the 3rd cycle, it was about 1.51 times more than the latter. With further increase in load, at the 4th cycle, the yield deformation was 0.93 times more than the previous one. At cycle 2, the column C4 has a yield displacement 1.51 times more than the 1st cycle. At the 3rd cycle, the yield displacement was 2.07 times more than the 2 nd cycle. After which at the 4th cycle, the yield displacement was 0.81 times more than the latter. The overall yield deflection is high at the initial cycles, but it was drastically resisted by the inclusion of basalt fibre.

At the 1st cycle, the yield deflection of column C2 is 0.53 times more than $\mathrm{C} 1$, whereas the yield deflection of column C3 is 0.48 times lower than C1. The yield deflection of column C4 was 0.32 times more than that of $\mathrm{C} 2$. At the 2nd cycle, the yield deflection of column C2 is 0.46 times more than C1, whereas the yield deflection of column C3 is 0.18 times lower than $\mathrm{C} 1$. The yield deflection of column C4 was 0.05 times more than that of $\mathrm{C} 2$. Considering the $3 \mathrm{rd}$ cycle, the yield deflection of column $\mathrm{C} 2$ is almost the same as $\mathrm{C} 1$, and the yield deflection of column $\mathrm{C} 3$ is 0.17 times more than C1. The yield deflection of column C4 was almost the same as that of C2. At the 4th cycle, the yield deflection of the columns with fibres was almost 1.3 times less than that of conventional whereas the column C 3 had a yield deflection 0.5 times more than $\mathrm{C} 1$.

\subsection{Ultimate Displacement}

The ultimate deflection from Figure 10 of columns $\mathrm{C} 1$ and $\mathrm{C} 3$ were found to be more than that of the columns C2 and C4. With each increment in load cycles, the ultimate deflection almost doubled than the previous one. The column C1 initially reported with more deformation, which was reduced with further increment in load cycles. But it did not sustain more loads. But column C2, had less deformation at initial load cycles yet it sustained comparatively more loads, and it lasted with more deformation. Akin kind of results was ascertained with columns $\mathrm{C} 3$ and $\mathrm{C} 4$ concerning columns $\mathrm{C} 1$ and $\mathrm{C} 2$.

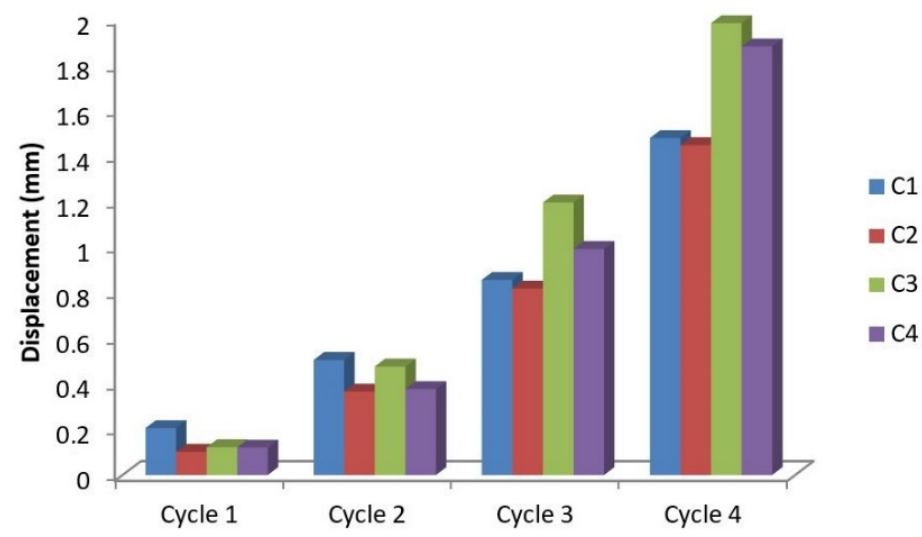

Figure 10 Ultimate Deflection of Column under each load cycle

\subsection{Residual Deflection}

The axial load-deformation curve of the columns was studied in detail to find out the residual deformation at the end of each cycle. Figure 11 shows the trace of residual deflection at the end of each load cycle. At the 1st and 2nd load cycle, there was no significant residual deflection. But at the 3rd cycle, the specimens had a residual deflection of about $1 \mathrm{~mm}$. With the further increment in load cycle, the residual deformation increased to about 0.75 times more for fibre reinforced concrete. At the end of the 5 th load cycle, the column $\mathrm{C} 2$ had a residual deformation of $3.5 \mathrm{~mm}$ whereas the column $\mathrm{C} 1$ and $\mathrm{C} 4$ had a residual deformation of $3 \mathrm{~mm}$. But the column $\mathrm{C} 3$ had a residual deformation of $2.5 \mathrm{~mm}$. The effect of residual deformation is more in fibre reinforced concrete as it could sustain large loads with more residual deformations. 


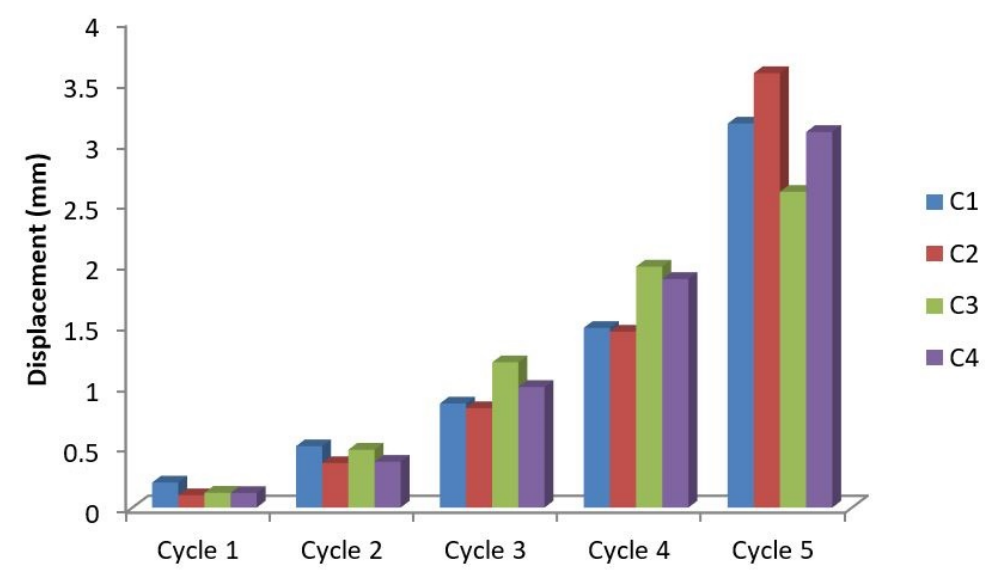

Figure 11 Residual deformation under each load cycles

\subsection{Energy Absorption Capacity}

The energy absorption capacity from Figure 12 of the column C2 is found to be $2.78 \%$ more than the column $\mathrm{C} 1$ whereas the energy absorption capacity of column C3 is $14.5 \%$ lower than that of column C1. The energy absorption capacity of column $\mathrm{C} 4$ is about $9.5 \%$ more than the column C3 and $8.3 \%$ lesser than column $\mathrm{C} 2$. The sintered fly ash lightweight concrete is designed to have a compressive strength similar to that of the normal weight concrete. Therefore it was intended to use in columns being a compression member. However, the behaviour of a material with effect to structural member depends on the ability of the reinforcement too (Mohammadamin Azimi. et al. (2015). With more confinement effects and with more resistance to load (Ebrahim Zamani Beydokhti, Hashem Shariatmadar. (2016) caused by the effect of reinforcement, the energy absorption capacity affects the behaviour of columns under vibration effects of loading.

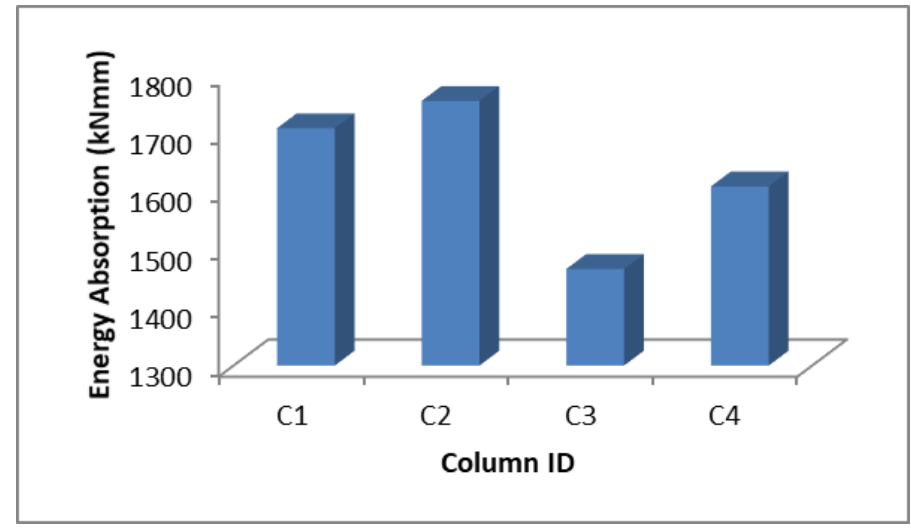

Figure 12 Energy Absorption capacity of columns

\subsection{Ductility}

In order to categorize the ductility of the specimens, an envelope curve was traced based on FEMA356 (2000). It can be ascertained from Figure 13 that the ductility factor of the column C2 was found to be $6.35 \%$ more and C3 is $15.08 \%$ more than that of $\mathrm{C} 1$, and the column $\mathrm{C} 4$ is pronounced with $11.19 \%$ less ductility factor than $\mathrm{C} 2$ in the 1 st load cycle. At the end of the 2 nd load cycle, the ductility factor of column C2 was found to be $36 \%$ more than that of $\mathrm{C} 1$ and column C3 is $15.32 \%$ more than that of C1. The column C4 had lesser ductility factor of about $1.39 \%$ when compared with C2.

The 3rd cycle is pronounced with ductility factors for C2 of about $3.74 \%$ lesser than C1and column C3 had $18.69 \%$ more than conventional $\mathrm{C} 1$. The ductility factor for column $\mathrm{C} 4$ in the previous cycles was found to be decreasing when compared to $\mathrm{C2}$, but now at the $3 \mathrm{rd}$ cycle, it was found to be $23.3 \%$ more than $\mathrm{C} 4$. At the end of the 4 th cycle, the ductility factor of column C2 was found to be $2.48 \%$ lesser than that of C1 and column C3 is $9.09 \%$ lower than that of $\mathrm{C} 1$. The column $\mathrm{C} 4$ had increased ductility factor of about $12.71 \%$ when compared with $\mathrm{C} 2$. At the end cycle, the ductility factors of all columns decreased to about $10 \%$ when compared with each other. 


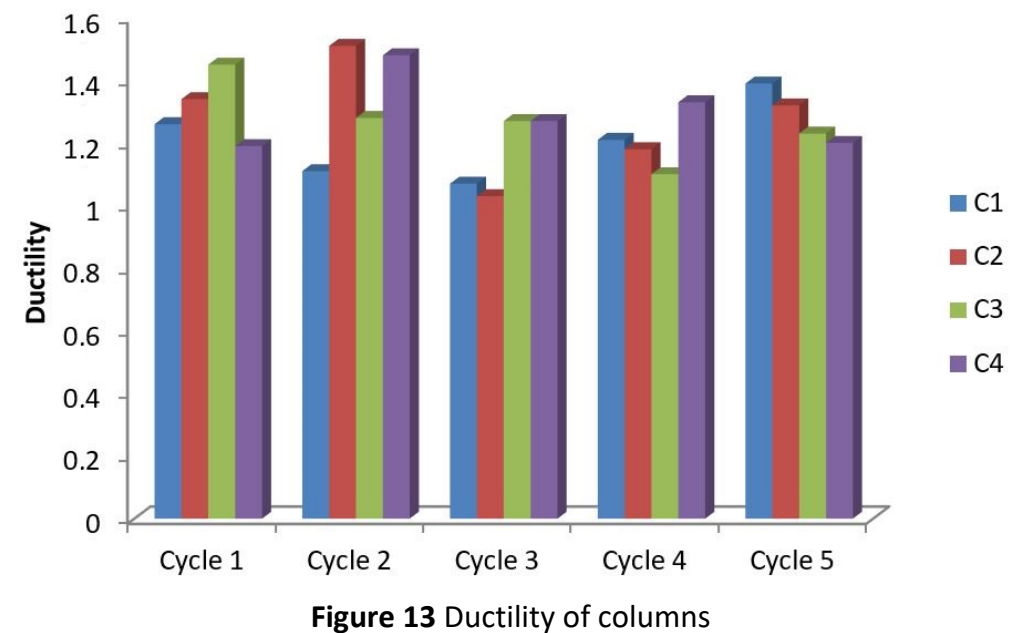

\section{COMPATIBILITY BETWEEN EXPERIMENTAL AND FINITE ELEMENT ANALYSIS}

\subsection{Strain Behaviour}

On observing the strain pattern obtained from finite element analysis from Figure 14, it can be noted that the columns with basalt fibre have strained up to 0.0035 . Whereas the columns without fibre had a strain of 0.002 , unlike the nature of concrete. The fig. shows the strain behaviour of columns at failure. The red colour contour indicates that it is the zone of formation of the plastic hinge and they are the points were actual failure had taken place. The strain pattern observed from finite element analysis exactly matches the failure pattern obtained from the experimental investigation.

The column $\mathrm{C} 1$ and $\mathrm{C} 3$ had plastic hinges formed at locations throughout the length of the specimen. The cracks were observed in the same places in experimental investigation. Whereas the column $\mathrm{C} 2$ was observed with crack and spalling just below the GFRP layer and small major cracks were seen at the bottom side where the strain is found to be maximum. Although the column $\mathrm{C} 4$ had a maximum strain at both top and bottom sides of the specimen, there was significant strain along the length of the specimen. 


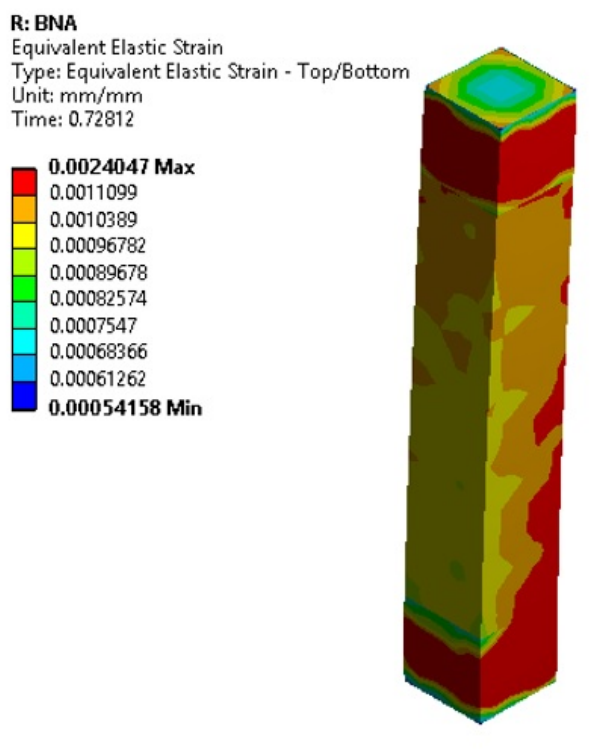

C1

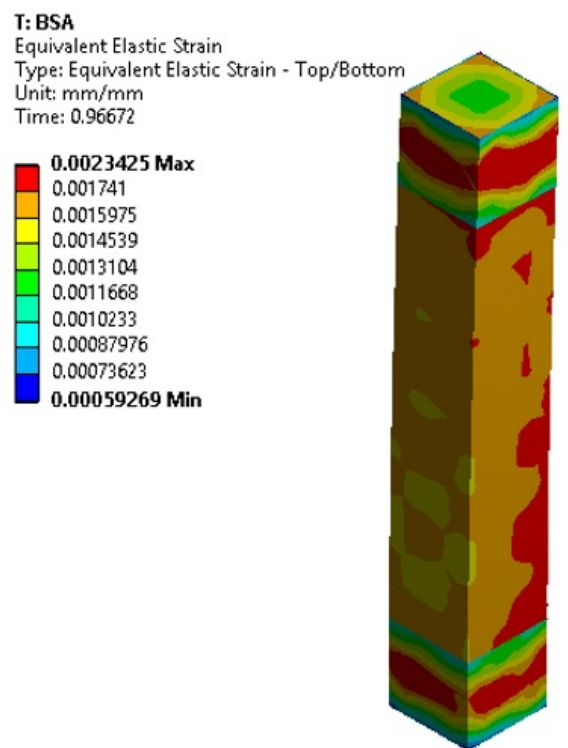

C3

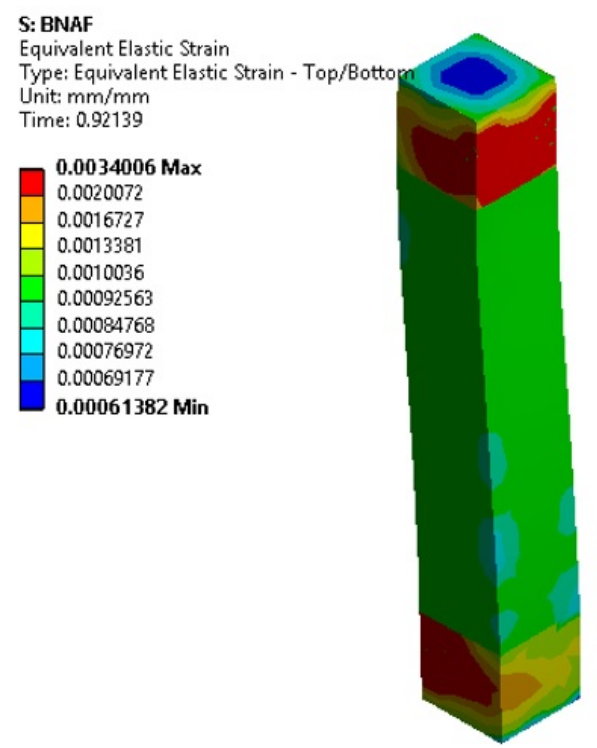

C2

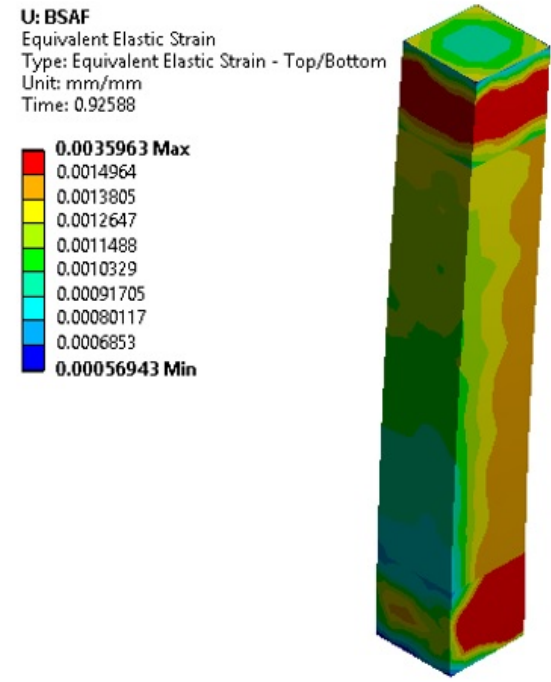

C4

Figure 14 Strain Behaviour of Columns obtained from FEA

\subsection{Deformation}

The load and deformations obtain through experimental analysis is compared with that of the numerical investigation and is shown in table 3 . The difference in Ultimate load-carrying capacity of the column $\mathrm{C} 1$ is $2.87 \%$, and the corresponding axial and lateral deformation is $2.81 \%$ and $7.67 \%$ respectively. Considering the Ultimate loadcarrying capacity of the column $\mathrm{C} 2$, it showed a difference of $3.68 \%$ and the corresponding axial and lateral deformations are $6.3 \%$ and $4.25 \%$ respectively. The column C3 showed $3.89 \%$ difference in Ultimate load carrying capacity and $3.6 \%$ difference in axial deformation, whereas the lateral deformation was about $7.42 \%$. The column C4 showed a $3.7 \%$ difference in Ultimate load carrying capacity and $4.15 \%$ and $5.73 \%$ difference in axial and lateral deformation, respectively.

It was observed that the FEA predicted the results almost higher than the experimental, but the experimental analysis and the FEA had a good agreement (Hossein Akbari Lor, Mohsen Izadinia, Parham Memarzadehv (2018) with the test results. The maximum error in prediction is 7.67\% (Mini Soman, Jebin Mohan (2018)). 
Table 3 Difference in results obtained

\begin{tabular}{cccccccc}
\hline & & \multicolumn{3}{c}{ Experiment } & & Finite Element Analysis \\
\cline { 3 - 8 } $\begin{array}{c}\text { SI } \\
\text { No }\end{array}$ & Column ID & $\begin{array}{c}\text { Ultimate } \\
\text { Load } \\
(\mathbf{k N})\end{array}$ & $\begin{array}{c}\text { Axial Shortening } \\
(\mathbf{m m})\end{array}$ & $\begin{array}{c}\text { Lateral } \\
\text { deformation at } \\
\text { mid-point } \\
(\mathbf{m m})\end{array}$ & $\begin{array}{c}\text { Ultimate } \\
\text { Load } \\
(\mathbf{k N})\end{array}$ & $\begin{array}{c}\text { Lateral } \\
\text { Axial Shortening } \\
(\mathbf{m m})\end{array}$ & $\begin{array}{c}\text { deformation at } \\
\text { mid-point } \\
(\mathbf{m m})\end{array}$ \\
\hline 1 & C1 & 374.40 & 1.48 & 0.30 & 385.14 & 1.52 & 0.33 \\
2 & C2 & 374.67 & 1.45 & 0.66 & 388.44 & 1.54 & 0.69 \\
3 & C3 & 366.18 & 1.98 & 0.26 & 380.44 & 2.05 & 0.28 \\
4 & C4 & 392.84 & 1.88 & 0.63 & 407.36 & 1.96 & 0.66 \\
\hline
\end{tabular}

\section{CONCLUSIONS}

From the experimental study, the following conclusions can be drawn out:

1. The load-carrying capacity of the battened built-up columns increased with the addition of basalt fibre.

2. The basalt fibre had no effect in axial deformation capacity of the columns, but it significantly affected the lateral deformation, energy absorption and ductility ratio of the columns.

3. The residual deflection with the addition of fibre is about 11.43 times more when compared with other columns.

4. The failure pattern observed after loading showed that the concrete is well confined between the built-up concrete sections.

5. Almost all failures were due to compression and crushing. The battened column could five load cycles with no sudden failure.

6. The experimental results had good agreement with that of the numerical analysis. The observed strain behaviour through numerical analysis proved that the failure had occurred only in the predicted places of occurrence of plastic hinges.

Author's Contributions: Conceptualization, N Divyah, R Thenmozhi and M Neelamegam; Methodology, N Divyah, R Thenmozhi and M Neelamegam; Investigation, N Divyah; Writing - original draft, N Divyah; Writing - review \& editing, N Divyah, R Thenmozhi and M Neelamegam; Funding acquisition, N Divyah; Resources, N Divyah; Supervision, N Divyah and R Thenmozhi.

Editor: Pablo Andrés Muñoz Rojas.

\section{References}

AISC. (2001). Load and resistance factor design specification for structural steel buildings. Chicago, IL: American Institute of Steel Construction.

Aslani F, Goel SC. (1991a) "Analytical criterion for buckling strength of builtup compression members". Engineering Journal, American Institute of Steel Construction, Vol. 28, pp. 159-168.

Aslani F, Goel SC. (1991b). "Stitch spacing and local buckling in seismic resistant double-angle braces". Journal of structural engineering division ASCE. Vol.117(8). Pp.2442-63.

Astaneh-Asl A, Goel SC, Hanson RD. (1985). "Cyclic out-of-plane buckling of double angle bracing”. Journal of Structural Engineering. Vol.111(5). pp.1135-53.

Behrokh Hosseini Hashemi, Alireza Poursamad Bonab. (2013). "Experimental investigation of the behavior of laced columns under constant axial load and cyclic lateral load". Engineering Structures. Vol. 57. PP.536-543.

BIS-800. Code of practice for general construction in steel.New Delhi: Bureau of Indian Standards; 2007. 
IS 801 : Code of Practice for Use of Cold Formed Light Gauge Steel Structural Members In General Building Construction. New Delhi: Bureau of Indian Standards; 1975(Reaffirmed 2001).

Bleich F. (1952). "Buckling strength of metal structures". 2nd edition. New York. McGraw-Hill Book Company.

Collins, M. P., Mitchell, D., and MacGregor, J. G. (1993). "Structural design considerations for high-strength concrete." Concrete International, 15(5), 27-34.

Dipti R. Sahoo, Durgesh C. Rai. (2007). "Built-up battened columns under lateral cyclic loading”.Thin-Walled Structures. Vol. 45. Pp. 552-562

Duan L, Reno M, Uang C.(2002). "Effect of compound buckling on compression strength of built-up members". Vol.39(1). Pp.30-7.

Ebrahim Zamani Beydokhti, Hashem Shariatmadar. (2016). "Behavior of Damaged Exterior RC Beam Column Joints Strengthened by CFRP Composites". Vol 13 No 5.

FEMA356- Prestandard and commentary for the seismic rehabilitation of buildings. Prepared by the American Society of Civil Engineering for the Federal Emergency Management Agency; 2000.

Galambos TV. (1998). “Guide to stability design criteria for metal structures”. 5th edition. New York: Wiley.

Hossein Akbari Lor, Mohsen Izadinia, Parham Memarzadeh. (2018). "Experimental and numerical study of I-shape slit dampers in connections". Latin American Journal of Solids and Structures. Vol.15(11)

IS 516.(1959). Methods of test for strength of concrete. Bureau of Indian Standards.

Jothimani B, Umarani C. 2019) "Experimental Investigation on Concrete Filled Steel Tubular Column to foundation Connections subjected to combined Axial and Lateral Cyclic Loading". Latin American Journal of Solids and Structures.Vol 16 No 6.

Lin FJ, Glauser EC, Johnston BG (1970). "Behavior of laced and battened structural member".Journal of structural engineering division ASCE. Vol.96(7). Pp.1377-401.

Mini Soman, Jebin Mohan. (2018). "Rehabilitation of RC columns using ferrocement jacketing". Construction and Building Materials. Vol. 181. Pp. 156-162

Mohammadamin Azimi, Azlan Bin Adnan, Abdul Rahman Bin Mohd Sam, Mahmood MD. Tahir. (2015). "Seismic Performance of Ductility Classes Medium RC Beam-Column Connections With Continuous Rectangular Spiral Transverse Reinforcements". Vol 12 No 4.

Muguruma, H., Nishiyama, M., Watanabe, F., and Tanaka, H. (1991). "Ductile behavior of high-strength concrete columns confined by highstrength transverse reinforcement." Proceedings of ACl International conference, Vol II, 877- 891.

S.M. Mourad, M.J. Shannag. (2012). "Repair and strengthening of reinforced concrete square columns using ferrocement jackets". Cement and Concrete Composites. Vol. 34. Pp.288-294

Sherif El-Tawil, Gregory G. Deierlein (1999). "Strength and Ductility of Concrete Encased composite Columns". Journal of Structural Engineering, pp.1009-1019.

Y.J. Kim, M-H. Kim, I.Y. Jung, Y. K. Ju, and S.D. Kim (2011). "Experimental investigation of the cyclic behavior of nodes in diagrid structures". Engineering Structures, Vol. 33 (7), pp. 2134-2144. 